\title{
An Introduction to Polycentricity and Governance*
}

\author{
Mark Stephan, Graham Marshall, and Michael McGinnis \\ Final version to appear in Andreas Thiel, William Blomquist, and Dustin Garrick, eds. \\ 2019. Governing Complexity. New York: Cambridge University Press, chap. 1, pp. 21-44.
}

\subsection{Polycentricity in Science, Local Politics and Governance}

Though our fundamental focus is on polycentric governance, in order to understand polycentric as an adjective that modifies the noun governance (defined below), we must start with the older term, polycentricity. According to Michael Polanyi, polycentricity had roots in the biological and chemical sciences and in the decentralized processes of decision- making within scientific communities (Polanyi 1964). The term had been used to describe the types of plants in botanical studies in the context of whether they have multiple reproductive cells (polycentric) or only a single reproductive cell (monocentric). The terms polycentric and monocentric are still used in this way in botany, and in other areas of scholarship and policy analysis. For example, many urban planning scholars and geographers use the term polycentric to refer to metropolitan regions which encompass both significant suburban centres and one major urban centre, in contrast to a monocentric metropolitan order centred about a single city that has greatly expanded over time.

Ostrom, Tiebout, and Warren (OTW) (1961) introduced the concept of polycentricity to the political science and public administration literatures as a way of making sense of the fact that most metropolitan areas in the United States lack a single dominant political leader, but instead include many local public authorities, each pursuing its own aims in a seemingly uncoordinated manner. Yet many such metropolises 'work', in the sense that economic growth, public safety, clean water, secure electrical power, and other local public goods are enjoyed by the residents.

Their basic point was that people living and working in densely populated communities want a wide range of local public goods, but different goods are most efficiently produced at different levels of spatial aggregation. Therefore, there is a certain logic to building political economic systems in which public jurisdictions and service delivery units of diverse sizes operate concurrently.

OTW $(1961,831)$ allude to the biological basis of the term in suggesting that a polycentric political system might instead be referred to as a 'multi- nucleated' political system, but since they were writing during the Cold War era, they had good reasons to bury that suggestion in a footnote. In any event, the conceptual leap from an organism with many reproductive centres to societal arrangements with 'many decision centres having limited and autonomous prerogatives and operating under an overarching set of rules' (Aligica and Tarko 2012) is a substantial move. Once this leap had been made by

\footnotetext{
* This material is based upon work supported by the National Science Foundation under Grant Number 1431487. Any opinions, findings, and conclusions or recommendations expressed in this material are those of the authors and do not necessarily reflect the views of the National Science Foundation.
} 
OTW, subsequent governance researchers rarely refer back to the chemical and biological basis of Polanyi's conceptualization, and instead focus on using it to better understand social, political, economic, and cultural systems where there is no hierarchy holding the whole system together.

It is worth noting that OTW never quoted nor cited Polanyi in their use of 'polycentric political system' as a concept. In an unpublished 1972 convention paper (subsequently reprinted in different forms in McGinnis 1999; V. Ostrom 1991), Vincent Ostrom admitted that he became aware of Polanyi's use of polycentricity only after the 1961 OTW article was published. But he also acknowledged that Polanyi's ideas connect well to the work on polycentricity by institutional scholars.

OTW $(1961,831)$ define polycentric (when referring to a political system) as follows: '[It] connotes many centres of decision-making ${ }^{1}$ which are formally independent of each other.' Polanyi's $(1951,184)$ statement that a 'polycentric task can be socially managed only by a system of mutual adjustments' has some overlap with OTW's (1961) conceptualization. But it took later scholars (see Aligica and Tarko 2012; Boettke and Aligica 2009; McGinnis 2005) to clarify the subtle links between the conceptualizations of Polanyi and Ostrom.

Despite the use by some scholars of polycentricity as equivalent to polycentric governance, we distinguish between polycentricity as it is understood in the social sciences (by both social science scholars broadly and by some in the subset of institutional scholars) and the particular use of polycentricity as it relates to governance alone. For example, when some, such as McGinnis $(2011,171)$, refer to polycentricity as a 'system of governance', we understand this in the context of the narrower term polycentric governance system rather than a statement that the wider term polycentricity applies only to structures and processes of decision-making. Polycentricity goes well beyond governance.

\subsubsection{Expanded Understanding of Governance}

As used by different scholars, the term polycentric governance may extend beyond the explicitly political activities engaged in by formal political units of government. ${ }^{2}$ For example, Ostrom points out in the 1972 unpublished convention paper mentioned above that he and his colleagues in 1961 had been directly concerned only with the actions of government officials, but that he had since realized that this concept also applied to broader understandings of governance. By highlighting the critical roles placed by private firms and non-profit organizations in the production and delivery of local public services in metropolitan areas, OTW (1961) were way ahead of their time. Only later did scholars working in other traditions grant private firms and community organizations a full role in the process of governance, in studies of collaborative governance and governance networks involving public, private, and voluntary

\footnotetext{
1 In this chapter, we use the term 'decision centre' to refer to formal organizations or more informal groupings which have established (or informally follow) procedures which designate certain individuals (in defined roles or positions) as having the authority to make decisions binding on that group as a whole. Decision centres are the fundamental units of polycentricity in social settings.

${ }^{2}$ In this chapter, we use 'political' in a traditional way. That is, we define as political those organizations and processes primarily and explicitly focused on the allocation of valued resources towards alternative ends desired by different groups within a society. If this allocation requires some coercion, the general expectation is that most members of that society consider these efforts as legitimate, rather than being extra-legal in nature. For instance, OTW focused on local public agencies within a metropolitan area that were directly involved in the selection, financing, or evaluation of local public goods. Only some of the organizations responsible for the actual production of those goods would fit this definition of explicitly political organizations, since many local public goods are produced by firms or voluntary organizations, often operating under contracts with or regulations set by public agencies.
} 
organizations. Ironically, the pioneering work of OTW had very little impact on this literature and is rarely cited by scholars of governance networks (McGinnis and Ostrom 2012).

We define governance as a 'process by which the repertoire of rules, norms, and strategies that guide behaviour within a given realm of policy interactions are formed, applied, interpreted, and reformed' (McGinnis 2011, 171). It is important to understand governance as a process, in which both government officials and non-governmental actors can play critical roles. Some non-governmental actors are directly connected to explicitly political matters (parties, interest groups, etc.), but private corporations and voluntary organizations of diverse types are often critical to the delivery of public services and the formation of public policy.

According to V. Ostrom, the concept of polycentricity encompasses economic markets, legal orders, scientific disciplines, and multi-cultural societies. Within the political realm, federalism may be the most prominent example of polycentricity. Although many students of federalism focus on the complex relationships among public agencies operating at the local, state, or national levels, V. Ostrom emphasized the important contributions made by public agencies operating across these levels, as well as organizations that would not generally be considered explicitly political, such as neighbourhood associations, inter-state compacts, community councils, and special districts defined for particular policy needs, such as fire protection, schools, and water management. Water resource management often involves numerous governments at different levels in intricate processes of decision-making, service delivery, facilities operation, and usage regulation. Just as governance has become recognized as broader than just the actions of governmental organizations, polycentric governance needs to be understood as a richer concept than federalism.

\subsubsection{Polycentric Systems and Arrangements}

Polanyi focused on polycentricity as a form of emergent order, in the sense that a complex system of component parts may exhibit regularized pat- terns which are only apparent if one looks at the system as a whole. Emergence is the appropriate analytical term because it is typically impossible to directly attribute these system-level regularities to specific actions taken by the constituent units. Even so, these regularities need to be included in any comprehensive analysis. Exactly this kind of emergence is seen as a critical component of polycentricity in all its forms.

To talk about a polycentric order is to say that regularized patterns have emerged, but that these decision centres maintain independence. OTW initially used system and order in reference to polycentricity, but the distinction between system and order in OTW is not entirely clear. For our purposes we are primarily concerned with governance, and we require a governance system to exhibit a more coherent form of order that expresses a greater level of what OTW referred to as taking 'each other into account' between the multiple decision centres. Thus, order can be understood as a matter of degree or in terms of its dimensionality. Poly- centric arrangements have some order and as the degree of order increases, the arrangements coalesce into a system.

We use the word system in relation to governance to denote the entirety of all the component decision centres that are interconnected beyond a mere formality. OTW said that decision-making centres constituted a system when a number of characteristics were fulfilled including options for competitive, contractual, or cooperative relationships. To call the decision centres significantly interconnected is our equivalent to OTW's taking each other into account. The term arrangement, when 
used with poly-centric, is an attempt to account for all cases of polycentric governance regardless of whether they rise to the level of a polycentric governance system. ${ }^{3}$ Thus, we use the phrase polycentric governance arrangements to capture all cases of polycentric governance including those that qualify as systems and those that do not. ${ }^{4}$

\subsubsection{Monocentric and Unitary Governments}

Monocentric governance is a phrase often used as the opposite of poly-centric by scholars working in this tradition, but we consider its use somewhat problematic. The phrase is rarely used in the broader public administration or political science literatures on governance. The standard terminology instead is unitary government, to which federal systems are typically contrasted. We argue here that monocentric and polycentric forms of governance are related in more subtle ways than are federal and unitary forms of government.

For the purposes of this volume, we define monocentric governance as a governance arrangement in which a single decision centre has ultimate authority over all important decisions related to the governance of that group or community. Certain specific tasks may be delegated to other decision units, but, ultimately, any decision by these delegated authorities can be overturned by the one uniquely designated ultimate centre for decision-making. ${ }^{5}$ Conversely, polycentric systems of governance lack any uniquely designated final authority. Other aspects of polycentric governance are discussed below, but it is this lack of a single ultimate authority that distinguishes polycentric governance. To preview what is said below, the existence of overarching rules does not themselves mean a form of governance moves from polycentric to monocentric. Because overarching rules can be agreed upon and enforced by the decision centres themselves (without an ultimate centre for decisionmaking), they can be understood as part of polycentric arrangements.

A governance system that truly consisted of only one decision centre would be unambiguously monocentric, but that has generally proved impractical for any significantly sized social system. However, systems of highly concentrated authority have proven quite feasible at lower levels of aggregation. Some family or kinship units, for example, can be accurately described as monocentric, and the organizational charts of many private corporations uniquely identify a chief executive officer with authority over all aspects of that organization. Since many other, more complex or ambiguous forms of corporate and family governance also exist, whereas truly monocentric systems at the societal level remain rare, there may be a natural limit to the size of viable monocentric governance structures. To put it another way, the greater feasibility of monocentric governance at lower levels of aggregation of decision centres leads us to expect to find that the incidence of polycentric governance increases with the level of aggre- gation. Evidence of this relationship is nevertheless yet to be established.

Vincent Ostrom $(1991 ; 1997)$ often used the Leninist organizational model to illustrate his understanding of a monocentric system of governance, and emphasized the practical limitations entailed by efforts to concentrate so much power in any single centre of authority. He realized that even totalitarian systems incorporate smaller organizations of diverse size and types, if only for the purposes

\footnotetext{
${ }^{3}$ Our use of this expression parallels E. Ostrom's use of 'institutional arrangements' as an umbrella term for the wide variety of institutionalized practices and practices that may range from simple rules-in-use to complex formal organizations.

${ }^{4}$ Villamayor-Tomás (2018) treats polycentric governance arrangements and systems as distinct, citing Marshall (2015). Marshall understands all systems to be a subset of the wider set of arrangements.

5 Polycentric governance can therefore be distinguished from certain 'decentralization' reforms where some implementation tasks are assigned to units but actual policymaking authority remains centralized.
} 
of implementing central commands. A clever supreme leader may purposefully establish multiple organizations engaged in internal policing or the protection of state secrets and use each of them as a check on the potential power of the other. We are convinced that this more nuanced interpretation of monocentric governance fits his meaning much better than using it as a simple foil for polycentric governance.

V. Ostrom similarly critiques the Hobbesian or Woodrow Wilsonian insistence of there being, somewhere in any viable system of societal governance, an ultimate source of authority, a single sovereign. For Wilson that role was played in the United States of America by Congress, for Hobbes by whatever actor satisfies his definition of a Leviathan (V. Ostrom 1991; 2008). For OTW, advocates of a single consolidated government at the metropolitan level were pursuing the chimera of a Gargantua topped by a single centre of ultimate authority. In truly polycentric governance, there is no single decision centre with ultimate authority. ${ }^{6}$

Under Leninist, Hobbesian, or Wilsonian interpretations, a monocentric governance system may include many subordinate centres and may allow for diverse forms of communication and contacts among them. These complications do not undermine the core defining aspect of a monocentric system, not as long as one decision centre is unambiguously identified as the ultimate authority. Such a monocentric governance system might manage to generate a recognizable form of order and could be said to constitute a coherent and well-coordinated system of governance. But the nature of the resulting order would be fundamentally at odds with the concept of polycentricity.

\subsubsection{Governance and Collective Goods}

The polycentric governance arrangements in which we are primarily interested entail processes of selection, production, financing, and evalu- ation of collective goods, as well as the management of common-pool resources. Governance necessarily requires tough decisions involving trade-offs among alternative goods, many of which are high priority items for different parts of society. Since the benefits of enjoying collective goods or common-pool resources cannot be easily limited to the individuals who invest their time and resources in providing those goods, some kind of authority is critical for solving the problems of free riding typically associated with the production of collective goods (Olson 1965). Typically, these authorities need to be able to enforce at least a minimal level of legitimate coercion to gather the resources needed to support public purposes, by requiring individuals to pay taxes or charging fees to individuals who seek access to more restricted goods.

V. Ostrom (2008) observed that traditional principles of public administration imply that this collective action should be organized monocentrically by 'government' as the ultimate source of authority, with its decisions implemented by elaborate hierarchies of officials. OTW (1961) acknowledged that a centralized political system can be appropriate for providing goods that broadly benefit the public at a single, large (e.g. national) scale (cf. Chapter 4). For most collective goods, however, they argued that any economies of scale achieved by centralization would likely be outweighed by diseconomies arising from the complexity of the required bureaucratic and hierarchical structures as well as the diversity of preferences and priorities within and among constituencies. They observed that this complexity tends to make overly centralized arrangements unresponsive to localized public interests, and provided an example where two or three years may be required to secure

\footnotetext{
${ }^{6}$ Although the public as a whole might be referred to as sovereign, it cannot be understood as a single decision centre since the dominant coalition of interests within the general population shifts over time.
} 
improvements to a sidewalk even where local residents have undertaken to cover the costs. A polycentric political system was seen as alleviating such unresponsiveness by enabling closer matching of the level of decision-making for a particular action to the level of the public that would benefit from it.

In a series of empirical studies of police services in several US metro- politan areas in the 1970s, Elinor Ostrom and her colleagues demonstrated the partial advantages that polycentric arrangements had over unitary forms of governance (McGinnis 1999b). Similarly, positive find-ings were demonstrated in later research on community-based management of common-pool resources, the work for which Elinor Ostrom received the 2009 Nobel Memorial Prize in Economic Sciences (E. Ostrom 1990; 2010). In both areas of the work, the central focus on multiple decision centres was apparent. Whether making sense of local collective action or understanding systems built on self- organization (or doing both simultaneously), polycentric governance served as a conceptual base. It was not postulated that monocentric governance was always inferior, but rather that polycentric governance was superior in some cases.

In effect, these empirical research programs demonstrated the real-world relevance of the general concept of polycentric governance in a limited range of empirical settings. The current volume continues in this same tradition, while also being more self-consciously attentive to the need to clearly define and measure the extent of polycentric governance present in different policy settings.

\subsection{Identifying the Characteristics of Polycentric Governance}

Polycentric governance is a complex term that has been used in different ways by different scholars. In Box 1.1 we list more than a dozen examples of definitions or other statements that illustrate various meanings of polycentricity or polycentric governance as used in the institutional literature.

In order to begin making headway on a common understanding of the variety of concepts associated with polycentric governance, we highlight those aspects most commonly employed by scholars in the field, followed by a discussion of less common aspects developed by some scholars. In the process we build a foundation for the use of these terms by the contribu-tors to this book.

\subsubsection{Central Aspects}

At the core of almost every definition of polycentric governance (or polycentricity, polycentric systems, or polycentric arrangements) is the idea of multiple centres of decision-making, or multiple authorities, no one of which has ultimate authority for making all collective decisions. The specific features of these multiple centres are rarely delineated. The necessary number of these centres in any given governance space is unclear. The basic idea implies that decision-making or service-provision units

are likely to vary in size, since not all public goods are most efficiently produced or delivered at the same level of aggregation (cf. Chapter 3). How many centres or how many different sizes exist is less important than the basic idea that multiple centres exist and operate concurrently, within a system in which no single centre has final ultimate authority. 


\section{Box 1.1 Varying perspectives on polycentric governance}

To give some sense of the various definitions given over the last fifty-five years, below are a sample of the ways in which the term polycentric governance (or its variants) has been used.

- The traditional pattern of government in a metropolitan area with its multiplicity of political jurisdictions may more appropriately be conceived as a 'polycentric political system'. 'Polycentric' connotes many centres of decision-making which are formally independent of each other. Whether they actually function independently, or instead constitute an interdependent system of relations, is an empirical question in particular cases. (OTW 1961, 831)

- $\quad[T]$ he critical variables of concern to scholars in the polycentric tradition include (1) individuals; (2) decision rules; (3) sets of events; (4) outcomes; and (5) measures of performance. (V. Ostrom 1972)

- Polycentricity refers to conditions where a pluralistic organizational structure reflects a pattern of power and influence characterized by many interdependent but relatively autonomous organizational units. (Toonen 1983, 251)

- Rearticulating the original OTW definition, V. Ostrom says that a polycentric system is a selforganizing system composed of '(1) many autonomous units formally independent of one another, (2) choosing to act in ways that take into account of others, and (3) through processes of cooperation, competition, conflict, and conflict resolution.' (V. Ostrom 1991, 225)

- Polycentric 'systems are the organization of small-, medium-, and large-scale democratic units that each may exercise considerable independence to make and enforce rules within a circumscribed scope of authority for a specific geographical area'. (E. Ostrom 2001, 2)

- Polycentric 'institutional arrangements [are] nested quasi-autonomous decision- making units operating at multiple scales. They involve local, as well as higher, organizational levels and aim at a finding a balance between decentralized and centralized control'. (Folke et al. 2005, 449)

- By 'polycentric' I mean a system where citizens are able to organize not just one but multiple governing authorities, as well as private arrangements, at different scales. (E. Ostrom 2003, in an interview conducted by Paul Dragos Aligica 2003, reprinted in Cole and McGinnis 2015, 61)

- A polycentric order is one where the elements of a complex system are allowed to make mutual adjustments to each other 'within a general system of rules where each element acts with independence of other elements'. (Aligica and Boettke 2009, quoting V. Ostrom 1972)

- [A] truly polycentric system is one in which governmental units both compete and cooperate, interact and learn from one another, and responsibilities at different governmental levels are tailored to match the scale of the public services they provide. (Cole 2011, 405, citing E. Ostrom 2009)

- Polycentricity thus describes a system of qualified independence among interdependent centres of authority. (Oakerson and Parks 2011, 154)

- Polycentricity is a system of governance in which authorities from overlapping jurisdictions (or centres of authority) interact to determine the conditions under which these authorities, as well as the citizens subject to these jurisdictional units, are authorized to act as well as the constraints put upon their activities for public purposes. (McGinnis 2011)

- [Polycentricity] is an institutional arrangement involving a multiplicity of decision centres acting independently but under the constraints of an overarching set of norms and rules that restrict externalities and create the conditions for an emergent outcome to occur at the level of the entire system via a bottom-up competitive process. (Aligica and Tarko 2013)

- Polycentric systems are complex adaptive systems without a central authority controlling the processes and structures of the system. Polycentric systems are characterized by multiple governance units at multiple scales, with each unit having some capacity to govern at its scale. (Garmestani and Benson 2013)

- Polycentric governance systems must fulfil at least two criteria to function as systems: presence of multiple centres of decision-making and coordination by an overarching system of rules. (PahlWostl and Knieper 2014, 140) 
Critical to the original definition from OTW (1961) was the notion that the decision-making centres were formally independent of each other and no single centre had ultimate authority of others. All centres retained significant autonomy from any other centre. At a minimum, formal independence could mean that decision centres could not simply do away with each other, i.e. that they possess enough autonomy to maintain their existence and cannot be abolished without reference to some overarching rules or processes. Beyond that minimum, formal independence could include some ability to contest adverse actions by other decision centres. At the same time, OTW observed that the extent to which these centres acted independently was an empirical question to be investigated in each case. Similarly, the extent of decision-making autonomy that is required has not been consistently delineated. For the sake of our work here, we treat independence and autonomy as synonymous terms.

Despite the centrality of formal (de jure) independence to the original definition of polycentric governance, we accept that there may be decision centres in such governance that have de facto independence. For example, subordinate units in a hierarchical organization might lack formal independence while also enjoying, in practice, significant levels of decision- making autonomy. For this reason, we include decision centres with de facto autonomy as part of a larger set of polycentric governance arrangements, in which other centres may have clearly defined de jure autonomy and de facto autonomy combined.

Alternatively, it is worth mentioning that there could be cases where decision centres are formally independent of one another, but lack de facto autonomy (e.g. where one centre has come to dominate others despite the formal independence). Such cases may be few, but we would consider them monocentric and not polycentric.

In addition, cases of polycentric governance are rife with jurisdictions whose connections are either formally absent or ambiguous and confusing, often by design. To consider one prominent example, the three branches of the US national government defined in the Constitution are formally independent, though functionally they are interdependent in numerous ways. The US Constitution serves as an overarching set of rules, but there is no higher-level institution that oversees all three branches. In addition, this Constitution leaves space for citizens to work together to establish new forms of collective action that were not specified in that document (including such critically important entities as political parties!). Many of the decision centres subsequently formed focus on matters of economics, professional expertise, religion, or community solidarity, resulting in a dazzling array of institutional diversity that must be considered an import- ant consequence of the way polycentric governance was set up at the constitutional level.

\subsubsection{Common Aspects}

Somewhat in tension with the notion of decision-making autonomy, OTW also emphasized the importance of the idea that the decision-making centres in a polycentric political system overlap in their areas of responsibility. The combination of autonomy and overlap is a critical aspect of polycentric governance.

The presence of overlapping jurisdictions is critical to the dynamism of polycentric governance, because without it, fewer decision centres would find it necessary to take each other into account when making decisions and taking actions. The sources of their overlap can be many, including interdependence between issues governed, the interconnectedness of the physical jurisdictions (e.g. 
water), or because functions of governance such as monitoring can be interdependent. Policy issues overlap in numerous ways, as can be seen with human health and environmental conditions. The notion of externalities assumes overlap. Similarly, the interconnected- ness of physical jurisdictions is seen readily around water as an environ- mental concern. Rivers are regularly used as both boundaries and points of connection. Functions of governance such as monitoring and evaluation can require many eyes from multiple locations to better understand the effectiveness of laws. For example, research on river basin management (Lankford and Hepworth 2010) has found that polycentric attempts at river basin management can help in situations where data monitoring is desired but is limited by resource constraints.

Polycentric governance spillover effects can occur between jurisdictions, regardless of overlap. Both overlapping jurisdictions and spillover effects help to increase the likelihood that decision centres will take each other's concerns and actions into account when making their own decisions.

By acknowledging the centrality of jurisdictional overlaps, OTW (1961) sought to counter the pervasive belief (then and now) that governmental overlaps invariably result in wasteful duplication of efforts, and that this duplication justifies movement towards consolidation. OTW argued that these overlaps recognized the reality of interdependencies among formally separate units and encouraged public officials in overlapping units to consider ways in which they might address their common concerns. In effect, overlaps guarantee both the need and the opportunity for authorities to engage in competition and cooperation among themselves. Though neither competition nor coordination will always be productive, there is the (high) potential for either to enhance the quality of the services provided across the jurisdictions. In this way, overlapping jurisdictions are the engine for actions, reactions, and interactions among all authorities involved.

From the earliest days of conceptualizing polycentric governance systems there has been an understanding that multiple decision centres take each other into account to some extent. They do so by engaging in regularized forms of interaction, which might take the form of competition, coordination, contractual relationships, consolidation, and other instruments for collective action. Since different forms of interaction may inspire them to develop different mechanisms for collective action, over time, a pervasive degree of institutional diversity will result. A high level of institutional diversity is a natural consequence of the long-term operation of polycentric processes.

Competition, contracts, partnerships, alliances, collaboratives, joint decision-making councils, the formation of higher-level authorities and other forms of coordination reflect different levels of conscious under- standings of the implications of interdependence. Different decision centres can compete, and thus be interdependent, with little awareness of each other. ${ }^{7}$ They can react to consumers of their services who, in turn, are the ones interacting across decision centres. Contracts are conscious actions where decision centres come to agreements concerning how each can help the other better achieve its own goals. Contractual relationships may be defined for limited periods of time, whereas partnerships or other forms of coordination require participants to adopt a more long-term and flexible attitude. In some circumstances, formerly independent decision centres may choose to join together into some larger governance units. Over time, new decision units will be formed and old ones dissolve, while others continue as before, or change in response to new challenges and opportunities.

\footnotetext{
${ }^{7}$ In this case, two decision centres may be taking each other into account less and mutually adjusting to one another more in the context of their interdependencies. Though we understand 'taking each other into account' as slightly more conscious and direct than 'mutual adjustment', for the sake of this chapter we treat these phrases as equivalents.
} 
Analysts of polycentric forms of governance stress the importance of low entry and exit costs, since that is the only way that individual consumers or voters, or the groups which represent them, will be able to choose from among alternative service providers or producers. This is an important source of dynamism in polycentric governance arrangements. Some level of competition among producers of similar goods seems inherent in most analyses of polycentric governance. In particular, low entry costs greatly facilitate the continued formation of new decision centres, as well as the innovation of new types of organizations or processes. Several analysts, such as Aligica and Tarko (2012) have insisted that an openness to the formation of new decision units is important to the underlying notion of polycentric governance.

\subsubsection{Dimensions of Polycentric Order}

Some analysts of polycentric arrangements dig more deeply into the motivating principles that lie behind these patterns of taking each other into account. Do actors adjust to each other only because they have to, once they come to realize the extent of their interdependence? Or do they mutually recognize each other's goals as legitimate concerns, and acknowledge a minimal sense of legitimacy to the actions of others? More generally, are these actors and their strategic options considered only on a one-off basis or are they connected together within a broader sense of community or legitimacy? Whether described as an 'overarching set of rules', an 'overarching set of norms and rules', or even as a 'general system of law', the concern here is whether there is a rule-based structure that manifests a shared sense of connection among these actors. In more informal terms, are they all playing the same game, according to a mutually agreed-upon set of rules for that game, or are they merely engaging with each other because they have to, but otherwise exist in a social vacuum?

When Polanyi discussed polycentric orders in biological or chemical systems, the search for a better understanding of the natural operation of physical laws provided the overarching context. For applications to governance, the nature of the overarching legal and normative context within which social interactions occur is rarely so obvious. For OTW this question was easily answered, because they were investigating forms of governance manifested in metropolitan areas in the United States of America, all of which were, in the final analysis, operating under the same laws, procedures, and shared legal understandings embedded in the US Constitution. When OTW (1961) consider the need for 'recourse to central mechanisms to resolve conflict', they find a ready example in the role of courts in settling both disputes among individual claimants and broader questions related to the Constitution itself. The courts are central authorities, but they derive that authority from the US Constitution, the overarching rules. When extended beyond this well-defined legal context, the relevant actors may or may not share a common sense of belonging to the same political or cultural system. Ostrom (1972) draws an analogy to Polanyi when he stresses the importance of a general system of rules for the successful operation of any form of polycentric governance. More recently, Aligica (2014) argued that polycentric governance is especially well-suited to multicultural societies, provided those groups have arrived at some minimal understanding of the nature of their constitutional foundation. The origin of this foundational constitutional ordering has been left unspecified in most accounts of polycentric governance, and yet, as the authors of Chapters 9 and 10 articulate, this is something that deserves careful attention in application to any empirical setting.

Polanyi was more directly concerned about establishing the logical basis for a different kind of order, namely, a regularized and persistent pattern of order which emerges automatically from interactions among the compon- ent units. The idea that polycentricity might create conditions for an 
emergent order or spontaneous order is critical in thinking about poly-centric governance. Emergence or spontaneity both express the sense that the orderly configuration of arrangements was not designed, directed, or ultimately controlled by any single centre of authority. An order wholly designed and controlled by a single centre is not consistent with poly- centric governance as understood here. For example, an empirical example of polycentric order arising through emergence can be seen in Northern Thailand (Tam-Kim, Uravian, and Chalad 2003) where water governance has developed through a diverse set of institutional arrangements and networks.

The question of emergence is of long-standing provenance in the study of complex adaptive systems, but this is not a topic that we can address in any detail here (cf. Chapter 4 ) But we do need to clarify the interrelated meanings of scale, levels, aggregation, and emergence, as they relate to the operation of polycentric governance.

Scholars writing about polycentric governance have at times treated scale and level as equivalents (e.g. Andersson and E. Ostrom 2008; E. Ostrom 2012), but we follow distinctions laid out by Gibson, E. Ostrom, and Ahn (2000). That is, 'scale' means 'The spatial, temporal, quantitative, or analytical dimensions used to measure and study any phenomenon.' 'Level' then means 'The units of analysis that are located at the same position on a scale.' This distinction allows us, in turn, to introduce the phrase 'levels of aggregation', which can be used to refer to the patterns of order that are most clearly perceived when an analyst focuses on interactions among actors operating primarily at the same level on a geographic scale. One complication is that the terms 'scale efficiencies' or 'economies of scale' actually relate to the production levels for goods, and not to the scale on which those efficiencies are to be measured. But these terms are so well-enshrined in the literature that we feel compelled to continue to use them.

With this distinction in mind, federalism requires a spatially based jurisdictional scale in which political authorities have jurisdictions defined at the distinct national, state and local levels. Typically, jurisdictional units at levels located lower on that scale are neatly nested with larger units organized at higher levels. When generalized to a polycentric system of governance, actors operating across those supposedly well-defined levels must also be considered, as would be collaborations involving jurisdictional units operating at distinct levels, or constituents of different jurisdictional levels who have decided to work together for common purposes, rather than trying to work through the leaders of their home jurisdictions. In situations of emergent order, interactions among units organized at one level tend to generate regularized patterns that can best be observed at a higher level of aggregation. In the most interesting cases, the pattern of order observable at the higher level was not among the goals being pursued by the component parts acting at lower level. For policy analysts, the classic example of emergent order was given to us by Adam Smith, in his concept of market efficiency emerging at the systemic level even though no individual producers or consumers consciously sought that outcome. He famously argued that the desirable outcome at the higher level occurred because lower-level actors were guided, as if by an invisible hand, to take actions that led to overall efficiency. Later economists defined the mathematical conditions under which that kind of emergent order can be assured, as well as identifying several complications that can arise along the way. To take the most notable example, purely voluntary exchange among individuals can rarely ensure the optimal production of goods that would benefit all members of that interacting system. Market failures of this kind need to be addressed in ways that step outside the strict boundaries of voluntary exchange, and this step moves us in the direction of considering broader contexts of polycentric order. We are not arguing that polycentric governance can ensure optimality any more than voluntary exchange. We are suggesting that polycentric governance may enhance other parts of a social system. 


\subsubsection{Polycentric Governance Systems}

As we continue to consider the dimensions of order in a political system, we recognize that some forms of order may have been consciously planned and reflect high-level goals pursued by some, though not all, of the constituent units. Many forms of coordination between actors in small- sized polycentric systems can be treated as a natural part of the options available to those actors. For example, OTW discuss both 'cooperative undertakings' and 'competition relationships' between decision centres, and they left as a question of empirical analysis the extent to which the interactions among multiple centres of limited and overlapping authority constituted an effective level of regular order. For systems of higher complexity, substantial direct efforts at systemic-level coordination may not seem consistent with the notion that order emerges in polycentric systems. But, direct efforts at systemlevel coordination will in a poly- centric governance setting lead to cascading adjustments by other decision centres, who in turn adjust to each other's adjustments, so that the outcome of the coordination effort is ultimately emergent despite any efforts to coordinate in a controlling manner (cf. Chapter 4).

The origin of systemic order is a point of some contention among scholars using the concept of polycentric governance. We think it is important to acknowledge that effective coordination within complex systems may emerge from the bottom up as a side-effect of other efforts (including competition), or it may result from explicit efforts by higher levels within that system (including explicit coordination). Elinor Ostrom and other analysts have demonstrated the ability of small-level community action to generate desirable outcomes on environmental and equity grounds. But there is no reason to presume that a polycentric system can include only small-sized decision centres. Clearly, someone with the wide scope of authority as the US President could engage in explicit efforts to make plans for the nation as a whole. His or her ability to actually implement such plans, however, is sharply limited by the concurrent activities of many other public officials, each with their own sphere of authority. Even so, presidents are often held accountable for facilitating the realization of a certain level of coordination among the various parts of the governmental system. Polycentric governance only precludes the total concentration of power or authority in any single actor. For example, in the area of climate change policy in the United States of America, a group of individual states in the northeast came together and created a regional initiative to cap and trade $\mathrm{CO} 2$ emissions in their states. This action happened in the absence of national policy. Even if national policy were to occur, the work would remain polycentric because of the necessary involvement of multiple levels of government.

Opinions differ on the question of whether system-wide coordination is a required condition for polycentric governance. Most would follow the lead of OTW and Polanyi in saying that even when there is no evidence of conscious efforts at coordination at the systemic level, a substantial level of regularity may still emerge from real-world examples of polycentric governance in action. For instance, OTW expected that public officials operating at lower than metropolitan-wide levels of authority would find ways to work together to realize at least some of their shared aspirations. It is reasonable to presume that similar efforts might take place among public officials with wider ranges of responsibility. When successful, those conscious efforts might well contribute to instances of successful coordination at the level of the political system as a whole.

Some definitions make a point of including coordination of the decision centres as a key characteristic of polycentric governance. For example, Pahl-Wostl (2009) (see Box 1.1 for an example) requires the regular achievement of effective levels of systems-wide coordination for governance to be 
classified as polycentric. We understand and appreciate her reasoning, but remain unconvinced that polycentric governance must necessarily include a high level of system-wide coordination. On the other hand, the mere existence of such a level of coordination would not disqualify that system from being treated as polycentric (according to how we have distinguished polycentric and monocentric governance) unless the coordination implied an entity that alone assumed a position of ultimate authority over all other decision centres within the system.

One way to balance these concerns is to require that to be considered well-performing, a polycentric governance system must manage, at a minimum, to successfully address at least some of the critical large-scale coordination problems that naturally arise in any complex array of institutional arrangements. Remember that OTW advocate polycentric governance as a means by which a wide range of collective goods, each of which is most efficiently produced or provided for at different levels of spatial aggregation, can be generated more effectively than if the entire governing apparatus was consolidated into a single centre of authority. Systemic coordination itself can be considered, in many circumstances, to constitute a collective good of value to actors who consciously pursue that goal, which suggests that some actors within a polycentric system might choose to directly address this problem, rather than hoping that the required level of coordination will somehow emerge on its own. In practice, both emergence and intentionality could contribute to realization of coordination at the systemic level.

Another reason to require fully realized polycentric governance to generate at least a minimal level of coordination can be justified by considering a core meaning of governance itself. The nature of political leadership is to find a balance between the competing goals and interests of that leader's constituents, while still managing to pursue the interests they share in common. Governance requires difficult decisions, and thus some may question whether an order that emerges purely spontaneously is worthy of the name governance. Others are quite comfortable calling uncoordinated actions of separate powers a form of emergent polycentric governance. For our part we continue to understand polycentric governance more as process than as end-state. To say that one situation or another constitutes 'governance' is not our primary task, but we do want to note the differences as seen by others (cf. Chapter 2).

When summarizing our discussion about characteristics of polycentric governance, we feel capable of providing a widely agreed-upon basic definition of polycentric, and therefore a basic definition of poly- centric governance, but we do not feel capable of providing a highly detailed definition that would be agreed upon by a large variety of scholars. ${ }^{8}$ Thus, we offer pared-down basic definitions as follows:

Polycentric: connotes multiple centres of decision-making authority which are de jure independent or de facto autonomous of each other.

Polycentric Governance: governance that has polycentric attributes, where governance is a process by which the repertoire of rules, norms, and strategies that guide behaviour within a given realm of policy interactions are formed, applied, interpreted, and reformed.

\footnotetext{
${ }^{8}$ For intriguing efforts to more fully characterize the logical structure of polycentric governance, see Aligica and Tarko (2012) and Carlisle and Gruby (2017). For reasons discussed in the text, we remain unconvinced that the literature on polycentric governance is yet ready to converge on any single representation of this complex and subtle concept.
} 
These definitions do not capture all of the key relevant characteristics. And we acknowledge that governance is a contested term in the literature. But as a start to understanding polycentric governance, it is solid. Next, we turn to eight characteristics (or dimensions) that in combination may begin to present a fuller, more detailed understanding of polycentric governance. In presenting these eight characteristics, we give scholars an opportunity to better recognize and make sense of governance under numerous contexts and to potentially further conceptualize the polycentric dimensions of governance

\subsection{Dimensions of Polycentric Governance}

The preceding discussion identified eight characteristics or properties that scholars have associated with the concept of polycentric governance (albeit while using diverse terms such as polycentricity, polycentric order, arrangements, etc.).

1. Multiple decision centres (which may be of varying sizes and types);

2. De jure independence or de facto autonomy of decision-making authority for each decision centre;

3. Overlapping jurisdictions in the range of authority for different decision centres (in addition to spillover effects of outcomes);

4. Multiple processes of mutual adjustment among decision centres (taking each other into account);

5. Low entry and exit costs for organizations or informal groupings;

6. An overarching system of rules (or laws, norms, and shared values);

7. Emergent patterns of behaviour, interactions and outcomes across decision centres;

8. A combination of emergent and intentional means of effective coordination at all levels of aggregation, from single decision centres to the system as a whole

We review these conceptual distinctions and operational suggestions, in order to facilitate empirical analyses of how outcomes of polycentric governance arrangements are shaped by the specific combinations of these components that are in place in particular settings. Each of these factors, considered separately, should prove amenable to empirical measurement. In Table 1.1 we provide examples of empirical measures that might be used to evaluate the extent to which the institutional forms in a particular setting exhibit the characteristics identified above. For reasons of space we cannot investigate these measures further in this chapter, but we note that several contributors to this book consider specific measures in detail (cf. Chapters 5, 6, 7 and 8 in Part II).

If we were to offer our own, more detailed definitions of polycentric governance and polycentric governance systems, we might start with the following points. First, polycentric governance would be any form of governance that has a mixture of the dimensions described above, but at the least would include the first and second characteristics. Each dimension can be logically arrayed from 'less' to 'more' in a way that is consistent with the basic definition of polycentric governance. Second, polycentric govern- ance systems would be based on the first four characteristics, at the least, but could include some degree of each of the second four characteristics. Third, we do not have the sense that more of a characteristic translates into a better outcome. Further empirical work is needed to better understand the relationship of the dimensions to outcomes. Finally, we have an underlying assumption for polycentric governance systems that they provide options for individuals to potentially reach 
preferred outcomes, including the option of collectively developing new kinds of options when other options fail. Failure remains an outcome, but futility does not.

Other relevant considerations remain for subsequent investigators. In order to evaluate the normative implications of different kinds of polycentric governance in different settings, for example, analysts would need to specify exactly which evaluative criterion should be considered. ${ }^{9}$ Trade-offs between desired criteria would, of course, be inevitable. Consider the question of the 'optimal' level of complexity in a given empirical setting. A more complex system of decision units would be more costly to keep running, for instance, but increased transaction costs could be offset by potential gains if the greater complexity provides improved resilience to changing circumstances.

Yet, there may be settings in which a specific kind of polycentric governance would be deemed preferable. For example, since coordination costs necessarily increase with the number of units participating in a given activity, in times of existential threat to an entire community it may be useful to concentrate decision-making authority more centrally than might be prudent in more ordinary times. Even so, there may be reasons for ensuring that other authorities maintain some oversight over the actions of central authorities, even in desperate times.

Although it would be premature to state conclusions at this early stage, we expect that each of the eight characteristics will need to be present, to at least a minimal degree, to ensure effective governance in any significant sector of policy concern. But before we can even ask questions concerning the 'optimal' degree of polycentric governance, we need solid measures of its magnitude in different cases, and along all relevant dimensions.

Although the values of different cases on any one characteristic might be relatively easy to compare, in terms of which case more fully exhibits that characteristic, we leave as a question for subsequent researchers to deter- mine how the overall multidimensional configuration of characteristics found in specific cases might be compared. We are confident that contributors to this book have provided useful clues towards subsequent investigations along those lines.

Ultimately, polycentric governance can be understood as an intrinsically dynamic process embedded within a contingent type of structure that is difficult to capture in simple measures. Yet this task may be critically important for anyone seeking to understand the foundation and the future evolution of political systems, democratic or not. Our belief is that this book goes a long way towards a theoretically rich, and an empirically grounded, understanding of polycentric governance. The next chapter concentrates on how an analyst might use the aspects and dimensions we have presented, in order to try to understand a governance situation involving multiple centres, and to determine whether and how it exhibits characteristics of polycentric governance.

\footnotetext{
${ }^{9}$ See Carlisle and Gruby (2017) for an interesting effort to trace out the normative implications of each contextual attribute that helps enable polycentric governance on three evaluative criteria: enhanced adaptive capacity, good institutional fit, or mitigation of risk on account of redundancy. Their analysis makes it clear that there is no configuration of polycentric governance that can simultaneously optimize all three criteria.
} 
Table 1.1 Potential measures for the eight characteristics of polycentric governance

\begin{tabular}{|c|c|}
\hline $\begin{array}{l}\text { Multiple decision centres (of } \\
\text { varying sizes and types) }\end{array}$ & $\begin{array}{l}\text { Multiplicity of decision centres: number of relevant units, } \\
\text { distribution of size of each (number of people, spatial scale, } \\
\text { magnitude of resources, scope of functional responsibilities); } \\
\text { distribution of decision structures (decision processes, degree of } \\
\text { formality, are decisions compulsory or voluntary?) }\end{array}$ \\
\hline $\begin{array}{l}\text { Formal independence / de facto } \\
\text { autonomy }\end{array}$ & $\begin{array}{l}\text { Range of decision latitude of each unit; measures of hierarchical } \\
\text { structure or resource dependence across decision units. }\end{array}$ \\
\hline $\begin{array}{l}\text { Overlapping jurisdictions (and } \\
\text { spillover effects) }\end{array}$ & $\begin{array}{l}\text { Proportion of people or resources under jurisdiction of multiple } \\
\text { decision units; number of decision units involved in specific types } \\
\text { of policy interactions or other measures of degree of functional } \\
\text { interdependence. }\end{array}$ \\
\hline $\begin{array}{l}\text { Multiple processes of mutual } \\
\text { adjustment among decision units }\end{array}$ & $\begin{array}{l}\text { Number and diversity of communication channels available to } \\
\text { (and used by) decision centres; number and relative use of } \\
\text { mechanisms to establish contracts, collaboratives, partnerships, } \\
\text { mergers, councils; number and relative use of legal forums, } \\
\text { options for arbitration, mediation, and other forms of alternative } \\
\text { dispute resolution. }\end{array}$ \\
\hline $\begin{array}{l}\text { Low costs of entry into or exit } \\
\text { from decision centres }\end{array}$ & $\begin{array}{l}\text { Economic, legal, and social transaction costs for joining or leaving } \\
\text { new decision centres (or for dismantling existing ones). }\end{array}$ \\
\hline $\begin{array}{l}\text { Overarching system of rules or } \\
\text { law }\end{array}$ & $\begin{array}{l}\text { Degree of convergence of beliefs, values, shared understandings, } \\
\text { values, norms, rules, and laws; extent of similarity in internal } \\
\text { structures of organizations or institutional processes (institutional } \\
\text { isomorphism). }\end{array}$ \\
\hline $\begin{array}{l}\text { Orderly patterns of behaviour, } \\
\text { interactions, and outcomes (may } \\
\text { be emergent) }\end{array}$ & $\begin{array}{l}\text { Regularity and predictability of behaviour of decision centres and } \\
\text { collective outcomes, such as stability of communication networks } \\
\text { and patterns of social interaction }\end{array}$ \\
\hline $\begin{array}{l}\text { Emergent or intentional means of } \\
\text { effective coordination and } \\
\text { decision- making at systems level }\end{array}$ & $\begin{array}{l}\text { Measures of successful achievement of goals shared by a high } \\
\text { proportion of individual citizens and/or decision centres; number } \\
\text { of decision units with authority that spans multiple decision units, } \\
\text { proportion of regulations enacted or implemented by higher } \\
\text { authorities; proportion of resources collected/spent by central } \\
\text { authorities }\end{array}$ \\
\hline
\end{tabular}




\section{Works Cited}

Aligica, Paul D. 2014. Institutional Diversity and Political Economy: The Ostroms and Beyond: Oxford University Press.

Aligica, Paul D., and Vlad Tarko. 2012. "Polycentricity: from Polanyi to Ostrom, and Beyond." Governancean international journal of policy administration and institutions 25 (2): 237-62.

Aligica, Paul D, and Vlad Tarko. 2013. "Co-Production, Polycentricity, and Value Heterogeneity: The Ostroms' Public Choice Institutionalism Revisited." American Political Science Review 107 (04): 726-41.

Andersson, Krister P., and Elinor Ostrom. 2008. "Analyzing decentralized resource regimes from a polycentric perspective." Policy Sciences 41 (1): 71-93.

Boettke, Peter J, and Paul D. Aligica. 2009. Challenging Institutional Analysis and Development: Routledge.

Carlisle, Keith, and Rebecca L. Gruby. 2017. "Polycentric Systems of Governance: A Theoretical Model for the Commons." Policy Studies Journal 10 (2): 629.

Cole, Daniel H., 2011. "From Global to Polycentric Climate Governance" Climate Law 2, 395-413.

Cole, Daniel H., and Michael D. McGinnis, eds. 2015. Elinor Ostrom and the Bloomington School of Political Economy, Volume 1: Polycentricity in Public Administration and Political Science: Lexington Books.

Folke, Carl, Thomas Hahn, Per Olsson, and Jon Norberg. 2005. "Adaptive Governance of Social-Ecological Systems." Annual Review of Environmental Resources 30 (1): 441-73.

Garmestani, Ahjond S., and Melinda Harm Benson. 2013. "A Framework for Resilience-based Governance of Social-Ecological Systems." Ecology \& Society 18 (1).

Gibson, Clark, Elinor Ostrom, and Ahn T.K. 2000. "The Concept of Scale and the Human Dimensions of Global Change." Ecological Economics 32 (271-239).

Lankford, Bruce, and Nick Hepworth. 2010. "The Cathedral and the Bazaar: Monocentric and Polycentric River Basin Management." Water Alternatives 3 (1): 82-101.

Marshall, Graham R. 2015. Polycentricity, subsidiarity and adaptive efficiency. A paper presented to the international workshop on polycentricity, Ostrom Workshop in Political Theory and Policy Analysis, Indiana University, Bloomington, Indiana USA, 14-17 December.

McGinnis, Michael D., ed. 1999. Polycentricity and Local Public Economies: Readings from the Workshop in Political Theory and Policy Analysis. Ann Arbor, MI: University of Michigan Press. 2005. "Beyond individualism and spontaneity: Comments on Peter Boettke and Christopher Coyne." Journal of Economic Behavior \& Organization 57 (2): 167-72. 2011. "An Introduction to IAD and the Language of the Ostrom Workshop: A Simple Guide to a Complex Framework." Policy Studies Journal 39 (1): 169-83. Updated version posted at https://doi.org/10.1111/j.1541-0072.2010.00401.x.

McGinnis, Michael D., and Elinor Ostrom. 2012. "Reflections on Vincent Ostrom, Public Administration, and Polycentricity." Public Administration Review 72 (1): 15-25.

Oakerson, Ronald J., and Roger B. Parks. 2011. "The Study of Local Public Economies: Multiorganizational, Multi-level Institutional Analysis and Development." Policy Studies Journal 39 (1): 147-67.

Olson, Mancur. 1965. The Logic of Collective Action. Cambridge: Harvard University Press. 
Ostrom, Elinor. 1990. Governing the Commons: The Evolution of Institutions for Collective Action. Cambridge University Press.

2001. "Vulnerability and Polycentric Governance Systems." IHDP (International Human Dimensions Programme on Global Environmental Change) Newsletter UPDATE no. 3. . 2003. "Rethinking Governance Systems and Challenging Disciplinary Boundaries: Interview with Paul Aligica," reprinted in Boettke and Aligica 2009 and Cole and McGinnis 2015). 2009. A Polycentric Approach for Coping with Climate Change, World Bank Policy Research Working Paper 509533 (Oct. 2009). 2010. "Beyond markets and states: Polycentric governance of complex economic systems." American Economic Review 100 (3). . 2012. "Nested Externalities and Polycentric Institutions: Must We Wait for Global Solutions to Climate Change Before Taking Actions at Other Scales?" Economic theory 49 (2): 353-69.

Ostrom, Vincent. 1972. "Polycentricity." Paper presented at Annual Meeting of the American Political Science Association. Reprinted in McGinnis 1999, pp. 52-74 and 119-138. 1991. The Meaning of American Federalism: Constituting a Self-Governing Society. San Francisco: Institute for Contemporary Studies Press. . 1997. The Meaning of Democracy and the Vulnerability of Democracies. A Response to Tocqueville's Challenge. Ann Arbor: The University of Michigan Press. . 2008. The Intellectual Crisis in American Public Administration. 3rd. Tuscalosa, USA: University of Arizona Press.

Ostrom, Vincent, Charles M Tiebout, and Robert Warren. 1961. "The organization of government in metropolitan areas: a theoretical inquiry." American political science review no. 55 (4):831-842.

Pahl-Wostl, Claudia. 2009. "A conceptual framework for analysing adaptive capacity and multi-level learning processes in resource governance regimes." Global Environmental Change-Human and Policy Dimensions19 (3): 354-65.

Pahl-Wostl, Claudia, and Christian Knieper. 2014. "The capacity of water governance to deal with the climate change adaptation challenge: Using fuzzy set Qualitative Comparative Analysis to distinguish between polycentric, fragmented and centralized regimes." Global Environmental Change 29:139-54.

Polanyi, Michael. 1951. The Logic of Liberty. Chicago: University of Chicago Press. . 1964. Science, Faith, and Society. Chicago: University of Chicago Press.

Tam-Kim, Yong, Pakping Uravian, and Bruns Chalad, eds. 2003. The Emergence of Polycentric Water Governance in Northern Thailand (Revised) 1: Oxford University Press.

Toonen, Theo A. J. 1983. "Administrative Plurality in a Unitary State: The Analysis of Public Organizational Pluralism," Policy \& Politics 11:3, 247-271.

Villamayor Tomas, Sergio. 2018. "Polycentricity in the water-energy nexus: A comparison of polycentric governance traits and implications for adaptive capacity of water user associations in Spain." Environmental Policy and Governance 28: 252-268. 